\title{
Comparison of Different Extraction Methods for Analysis of 10 Organochlorine Pesticides: Application of MAE-SPE Method in Soil from Beijing
}

\author{
Shanshan $\mathrm{Di}^{1} \cdot$ Shengchao Shi $^{1} \cdot$ Peng $\mathrm{Xu}^{2} \cdot$ Jinling Diao $^{1} \cdot$ Zhiqiang Zhou $^{1}$
}

Received: 6 October 2014/ Accepted: 2 April 2015/Published online: 3 May 2015

(C) Springer Science+Business Media New York 2015

\begin{abstract}
Four commonly applied extraction techniques for organochlorine pesticides, microwave-assisted extraction (MAE), accelerated solvent extraction (ASE), quick, easy, cheap, effective, rugged, and safe (QuEChERS) extraction and ultrasonic solvent extraction, were applied on soil samples in order to evaluate their performances. The extracts were analyzed by GC-ECD and confirmed by GC-MS/MS. The MAE and QuEChERS extraction methods generally yielded higher results compared to the ultrasonication and ASE methods, while the lowest recovery (56.8\%) for $o, p^{\prime}$-DDD was obtained using the QuEChERS method. The MAE method was further applied to six different soils from Beijing. In the soil samples only $\alpha$-endosulfan and $\beta$-endosulfan were not detected. The ratios of $\alpha-\mathrm{HCH} / \gamma-\mathrm{HCH}$ and $\alpha-\mathrm{HCH} / \beta-$ $\mathrm{HCH}$ indicated $\mathrm{HCH}$ residues likely originated from historical use of HCHs, and that technical HCHs were not likely being currently applied in Beijing.
\end{abstract}

Keywords Organochlorine pesticides .

Extraction methods - Purification methods .

Methods comparison · Soils

Organochlorine pesticides (OCPs) are effective pest control chemicals that were used globally in agriculture from the 1950s to the mid-1980s (Chikuni et al. 1997). These

Zhiqiang Zhou

zqzhou@cau.edu.cn

1 Department of Applied Chemistry, China Agricultural University, Yuanmingyuan West Road 2, Beijing 100193, People's Republic of China

2 Research Center for Eco-Environmental Sciences, Chinese Academy of Sciences, Shuangqing RD 18, Beijing 100085 , People's Republic of China compounds are now avoided due to their high bioaccumulation potential, persistence in the environment, and high toxicity to non-target organisms (Jia et al. 2007; Loganathan and Kannan 1994). They are classified as typical persistent organic pollutants (POPs) (Zhao et al. 2012).

Although many OCPs have been banned in most countries for almost 40 years, high residue concentrations are still detected in almost all environmental media, including air (Pozo et al. 2008), soil (Tao et al. 2008), plant (Srivastava et al. 2006), animal (Gebbink et al. 2007), and even human tissues (Zietz et al. 2008). Soil is the principal reservoir of environmental pesticides and plays an important role in the global distribution and fate of OCPs. The OCPs retained in soils are bound to soil organic matter (OM) through covalent bonds, hydrophobic interactions and diffusion-controlled partitioning (Zhang et al. 2011b). The OCPs not only have a large retention capacity but also re-emit these old organic pollutants into the atmosphere, ground water and living organisms as a secondary source (Zhang et al. 2013).

The extraction of OCPs from soils is a critical sample preparation step. Microwave-assisted extraction (MAE) has been considered as a realistic and effective alternative to conventional solvent extraction methods. In recent years, the extraction of organic compounds by microwave irradiation, as originally proposed by Ganzler et al. (1986), has been used to analyze environmental contaminants, such as polycyclic aromatic hydrocarbons (PAHs), pesticides, polychlorinated biphenyls (PCBs), and phenols, from various solid and liquid matrices (Pino et al. 2000; Parera et al. 2004; Zhang et al. 2012b). In general, all of these methods are effective, but they vary in their requirements for time and solvent volume.

In this study, the performance characteristics of different extraction techniques, including MAE, ASE, ultrasonic 
solvent extraction and quick, easy, cheap, effective, rugged, and safe (QuEChERS) extraction were compared for determination of 10 OCPs in soil. Then, the MAE method was applied to real samples from Beijing, and the extracts were analyzed by GC-ECD and confirmed by GC-MS/MS.

\section{Materials and Methods}

For this study, 10 OCPs were analyzed: $\alpha-, \beta-$ and $\gamma-\mathrm{HCH}$, $o, p^{\prime}$-DDT, $o, p^{\prime}$-DDD, $o, p^{\prime}$-DDE, cis-chlordane, transchlordane, $\alpha$-endosulfan, and $\beta$-endosulfan. Pesticide standards (purity $>99.0 \%$ ) were obtained from $\mathrm{J} \& \mathrm{~K}$ Scientific Ltd (Beijing, CN). The recovery surrogate 2,4,5,6-tetrachloro-m-xylene (TCMX) and internal standard (IS) pentachloronitrobenzene were also purchased from J\&K Scientific Ltd. Acetone, $n$-hexane, acetonitrile, and petroleum ether $\left(60-90^{\circ} \mathrm{C}\right)$ were pesticide grade and purchased from Sinopharm Chemical Reagent Co., Ltd (Shanghai, CN).

The study area for this investigation was Beijing, located in the northern China. Soil was collected from 6 sampling sites, and the physicochemical properties of the soils are listed in Table 1. After the superficial layer of 1-2 cm was removed, the soil was collected to a depth of $10 \mathrm{~cm}$ and put into a plastic bag with a zip lock, then transported to the laboratory. After removing stones and residual roots, the samples were freeze-dried, thoroughly mixed, sieved through a $2 \mathrm{~mm}$ mesh sieve, and then stored at $-20^{\circ} \mathrm{C}$ until analysis.

OCP analyses were carried out on an Agilent GC-ECD HP-7890A series system with a HP-5 column (30 m, $0.32 \mathrm{~mm}$ i.d., $0.25 \mu \mathrm{m}$ film; Agilent Technologies Inc. Palo Alto, CA, USA). High-purity $\mathrm{N}_{2}(99.999 \%)$ was used as the carrier gas, and the flow rate was $1.0 \mathrm{~mL} / \mathrm{min}$. The injector and detector temperatures were 270 and $290^{\circ} \mathrm{C}$, respectively. The oven temperature program was as follows: initial temperature began at $90^{\circ} \mathrm{C}$ for $1 \mathrm{~min}$, increased to $180^{\circ} \mathrm{C}$ at $15^{\circ} \mathrm{C} / \mathrm{min}\left(5 \mathrm{~min}\right.$ hold time), to $185^{\circ} \mathrm{C}$ at $5^{\circ} \mathrm{C} / \mathrm{min}(11.5 \mathrm{~min}$ hold time $)$, to $225^{\circ} \mathrm{C}$ at $35^{\circ} \mathrm{C} / \mathrm{min}$
(1 min hold time), and finally increased to $270^{\circ} \mathrm{C}$ at $20^{\circ} \mathrm{C} /$ min ( 3 min hold time). One $\mu \mathrm{L}$ of sample was injected in splitless mode.

The identities of OCPs in the samples were confirmed using a Thermo Trace-Ultra gas chromatograph coupled to a triple quadrupole mass detector Thermo TSQ Quantum (Waltham, MA, USA). The separation was performed on a Thermo Scientific TRACE TR-35MS column (30 m, $0.25 \mathrm{~mm}$ i.d., $0.25 \mu \mathrm{m}$ film thickness). Helium was used as carrier gas at a constant flow rate of $1.0 \mathrm{~mL} / \mathrm{min}$. The ion source and MS transfer temperature was 250 and $280^{\circ} \mathrm{C}$, respectively. GC conditions were as follows: initial column temperature $90^{\circ} \mathrm{C}(1 \mathrm{~min})$, increased at $25^{\circ} \mathrm{C} / \mathrm{min}$ to $210^{\circ} \mathrm{C}$, held for $15 \mathrm{~min}$, then $20^{\circ} \mathrm{C} / \mathrm{min}$ to $218^{\circ} \mathrm{C}$, and held for $5 \mathrm{~min}$, then $20^{\circ} \mathrm{C} / \mathrm{min}$ to $270^{\circ} \mathrm{C}$, and held for $5 \mathrm{~min}$.

Microwave-assisted extraction (MAE) was carried out with a Mars 6 Xpress laboratory microwave extraction system (CEM, Matthews, NC, USA). The instrument is able to concurrently extract 40 solid samples in PTFE extraction vessels in a single step. Soil samples $(5 \mathrm{~g})$ were accurately weighed out and transferred into the microwave extraction vessels. The solvent selected for the extraction was petroleum ether-acetone $(1: 1, \mathrm{v} / \mathrm{v})$. This mixture is one of the most adequate solvents for the extraction of OCPs, because good recoveries are obtained when the mixture is used and the time consumed in the evaporation step is small. Thirty $\mathrm{mL}$ aliquots of petroleum ether-acetone were added to the vessels, and then the sample was manually shaken for $2 \mathrm{~min}$ for homogenization. The extraction conditions were as follows: the temperature was ramped to $100^{\circ} \mathrm{C}$ over $5 \mathrm{~min}$ and held for $10 \mathrm{~min}$, then cooled down for $15 \mathrm{~min}$. The microwave power was $800 \mathrm{~W}$. After extraction, the extracts were filtered through $5 \mathrm{~g}$ of anhydrous sodium sulfate for dehydration, transferred to a pearshaped flask, and concentrated to dryness using a RE-52A rotary vacuum evaporator in a water bath at $35^{\circ} \mathrm{C}$.

Accelerated solvent extraction (ASE) was carried out with an ASE 350 extractor (Dionex, Sunnyvale, CA, USA). The extraction program for solid samples was as follows: $5 \mathrm{~g}$ soil was mixed with $2.5 \mathrm{~g}$ bergmeal in a $34 \mathrm{~mL}$

Table 1 Physicochemical properties of the soil samples

\begin{tabular}{|c|c|c|c|c|c|c|}
\hline Soil type & $\begin{array}{l}\text { Xiaotangshan } \\
\text { Sandy loam }\end{array}$ & $\begin{array}{l}\text { Liulin } \\
\text { Silt loam }\end{array}$ & $\begin{array}{l}\text { Xixiaoying } \\
\text { Loam }\end{array}$ & $\begin{array}{l}\text { Shangzhuang reservoir } \\
\text { Sandy loam }\end{array}$ & $\begin{array}{l}\text { CAU } \\
\text { Loam }\end{array}$ & $\begin{array}{l}\text { Tiangongyuan } \\
\text { Loam }\end{array}$ \\
\hline Organic matter, $\mathrm{g} / 100 \mathrm{~g}_{\mathrm{dwt}}$ & $42.0 \pm 0.5$ & $14.2 \pm 0.4$ & $14.5 \pm 0.2$ & $5.4 \pm 0.1$ & $8.6 \pm 0.1$ & $3.8 \pm 0.1$ \\
\hline Clay $(<2 \mu \mathrm{m}), \%$ & $10.8 \pm 0.1$ & $26.8 \pm 0.1$ & $24.8 \pm 2.8$ & $16.8 \pm 2.8$ & $16.8 \pm 2.8$ & $16.8 \pm 2.8$ \\
\hline Silt $(<20-2 \mu \mathrm{m}), \%$ & $20.0 \pm 5.7$ & $52.0 \pm 0.1$ & $44.0 \pm 0.1$ & $18.0 \pm 8.5$ & $40.0 \pm 0.1$ & $36.0 \pm 5.7$ \\
\hline Sand $(2000-20 \mu \mathrm{m}), \%$ & $69.2 \pm 5.7$ & $21.2 \pm 0.1$ & $31.2 \pm 2.8$ & $65.2 \pm 5.7$ & $43.2 \pm 2.8$ & $47.2 \pm 2.8$ \\
\hline $\mathrm{pH}$ & $8.34 \pm 0.02$ & $8.32 \pm 0.01$ & $8.21 \pm 0.06$ & $7.88 \pm 0.03$ & $8.35 \pm 0.01$ & $8.61 \pm 0.03$ \\
\hline
\end{tabular}

$C A U$ China Agricultural University 
stainless steel vessel, then $10 \mathrm{~g}$ quartz sand was placed in the vessel. Acetone: petroleum ether $(1: 1, \mathrm{v} / \mathrm{v})$ was used as the extraction solvent at $110^{\circ} \mathrm{C}$ under a pressure of $1500 \mathrm{psi}$ with $6 \mathrm{~min}$ for heating. The extraction was carried out in two cycles with $5 \mathrm{~min}$ static extraction. In the end, the extraction cell was flushed with solvent $(60 \%$ of the cell volume) and purged with nitrogen (60 s). The extracts were concentrated to dryness by rotary evaporation.

Ultrasonication extraction was performed with a KQ 5200DB extractor (Kunshan, CN) over a period of $30 \mathrm{~min}$ using $20 \mathrm{~mL}$ of acetone: petroleum ether $(1: 1, \mathrm{v} / \mathrm{v})$ as the solvent. Then the polypropylene centrifuge tubes were centrifuged at $3500 \mathrm{rpm}$ for $3 \mathrm{~min}$. The extraction was repeated twice using fresh solvent. The combined solvent phase was filtered through $5 \mathrm{~g}$ of anhydrous sodium sulfate and evaporated to dryness on a vacuumed rotary evaporator at $35^{\circ} \mathrm{C}$.

A QuEChERS extraction procedure was also used to compare the extraction efficiency with the above-mentioned methods. The spiked soil $(5 \mathrm{~g})$ was accurately weighed and put into a $50 \mathrm{~mL}$ polypropylene centrifuge tube. Three $\mathrm{mL}$ of water and $7 \mathrm{~mL}$ of acetonitrile were added, and the mixture was vortex-mixed for $1 \mathrm{~min}$. Afterwards, $6 \mathrm{~g}$ magnesium sulphate $\left(\mathrm{MgSO}_{4}\right), 1.5 \mathrm{~g}$ sodium chloride $(\mathrm{NaCl}), 0.75 \mathrm{~g}$ disodium citrate sesquihydrate $\left(\mathrm{Na}_{2} \mathrm{HCit} \cdot 1.5 \mathrm{H}_{2} \mathrm{O}\right)$ and $1.5 \mathrm{~g}$ sodium citrate dihydrate $\left(\mathrm{Na}_{3} \mathrm{Cit} \cdot 2 \mathrm{H}_{2} \mathrm{O}\right)$ were added and vortex-mixed to prevent salt agglomeration. Then the mixture was sonicated in an ultrasonic bath for $1 \mathrm{~min}$ and centrifuged at $4000 \mathrm{rpm}$ for $10 \mathrm{~min}$. The supernatant was transferred to a glass pearshaped bottle and concentrated to dryness with a rotary vacuum evaporator $\left(35^{\circ} \mathrm{C}\right)$.

After extraction, three purification methods were used to compare the purification capacity. The first method was solid phase extraction. A Florisil-SPE cartridge $(1000 \mathrm{mg}$, $6 \mathrm{~mL}$, Agilent SampliQ Products) was used to clean up interfering substances. The cartridge was preconditioned by rinsing with $10 \mathrm{~mL}$ of acetone followed by $5 \mathrm{~mL}$ of $n$ hexane and equilibrated with $5 \mathrm{~mL}$ leachate (acetone: $n$ hexane $=1: 15, \mathrm{v} / \mathrm{v})$. The elution was performed with $6 \mathrm{~mL}$ leachate. The eluate was concentrated to dryness under a gentle nitrogen flow, and diluted to $1.5 \mathrm{~mL}$ with $n$ hexane, and $100 \mu \mathrm{L}$ internal standard was added.

The second method was as follows: after the extracts were concentrated to dryness, $10 \mathrm{~mL} n$-hexane and $5 \mathrm{~mL}$ $98 \% \mathrm{H}_{2} \mathrm{SO}_{4}$ were added to the glass pear-shaped bottle. The same purification step was repeated twice, and then $2 \times 10 \mathrm{~mL}$ of $2 \% \mathrm{Na}_{2} \mathrm{SO}_{4}$ aqueous solution was added for washing. The supernatant was filtered through $5 \mathrm{~g}$ of anhydrous sodium sulfate for dehydration and evaporated to near dryness on a vacuumed rotary apparatus. The residue was reconstituted in $1.5 \mathrm{~mL}$ of $n$-hexane, and $100 \mu \mathrm{L}$ internal standard was added prior to analysis by gas chromatography.

The third method was as follows: after the extracts were concentrated to dryness, $1.5 \mathrm{~mL} n$-hexane and $100 \mu \mathrm{L}$ internal standard were added to the glass pear-shaped bottle. One $\mathrm{mL}$ supernatant was removed and transferred to the clean-up tube containing $50 \mathrm{mg}$ of PSA (primary secondary amine), $150 \mathrm{mg}$ of $\mathrm{MgSO}_{4}$ and $50 \mathrm{mg}$ of C18. The tubes were capped tightly and shaken by the vortex for $1 \mathrm{~min}$, followed by centrifugation. Prior to instrument analysis, the supernatant was filtered through a $0.45 \mu \mathrm{m}$ filter.

\section{Results and Discussion}

Recovery efficiency is an important factor when the analytical method is evaluated. Table 2 shows the recoveries and RSD of 10 OCPs extracted from the spiked soil sample using different extraction methods. Ultrasonication and ASE extraction were found to yield lower recoveries. In most cases, the recoveries for these two methods were below $70 \%$, especially for $\beta$-endosulfan. The high volatility of $\beta$-endosulfan resulted in a greater loss for ASE when the sample was purged with nitrogen. For ultrasonification, the increased movement of the molecules of compound and the high volatility of $\beta$-endosulfan led to the very low result. These results indicated that ultrasonification and ASE were unsuitable methods to effectively extract the 10 OCPs under these experimental conditions. Several studies also reported that ASE had a lower extraction recovery than MAE when the OCPs were determined in vegetable samples (Barriada-Pereira et al. 2007). The MAE and QuEChERS extractions generally yielded higher results compared to the ultrasonication and ASE extractions. In most cases, the recoveries for MAE and QuEChERS were between $80 \%$ and $120 \%$. However, the lowest recovery (56.8\%) for $o, p^{\prime}$-DDD was obtained using QuEChERS method. Moreover, the recoveries of $\alpha-\mathrm{HCH}$ and $\beta-\mathrm{HCH}$ with QuEChERS extraction were over $120 \%$. It may be attributed to several causes. The first might be the interferences of the matrix also known as "matrix induced chromatographic response enhancement" effect. Another reason could be the matrix effect on transfer of compounds from the injection port, because major components may compete for the active sites of the liner, enabling transfer of larger amounts of analytes into the column (Zhang et al. 2011c). In addition, QuEChERS yielded relatively higher RSD values compared to MAE, which indicated that MAE could provide more robust and repeatable results under the specified extraction conditions in this study. Thus, MAE was selected for further work based on a combination of 
Table 2 Extraction efficiencies for MAE, QuEChERS, ultrasonification and ASE

\begin{tabular}{|c|c|c|c|c|c|c|c|c|}
\hline & \multicolumn{2}{|l|}{ MAE } & \multicolumn{2}{|c|}{ QuEChERS } & \multicolumn{2}{|c|}{ Ultrasonification } & \multicolumn{2}{|l|}{ ASE } \\
\hline & $\mathrm{R}(\%)$ & $\operatorname{RSD}(\%)$ & $\mathrm{R}(\%)$ & RSD (\%) & $\mathrm{R}(\%)$ & RSD (\%) & $\mathrm{R}(\%)$ & $\operatorname{RSD}(\%)$ \\
\hline$\alpha-\mathrm{HCH}$ & 102.8 & 1.9 & 123.4 & 6.0 & 91.4 & 4.3 & 89.8 & 4.1 \\
\hline$\beta-\mathrm{HCH}$ & 100.3 & 4.1 & 124.1 & 8.5 & 88.9 & 6.3 & 76.4 & 4.0 \\
\hline$\gamma-\mathrm{HCH}$ & 95.5 & 1.8 & 102.2 & 6.8 & 67.6 & 3.5 & 65.8 & 2.3 \\
\hline trans-Chlordane & 96.4 & 3.7 & 98.8 & 6.9 & 58.9 & 3.2 & 52.9 & 2.2 \\
\hline$o, p^{\prime}-\mathrm{DDE}$ & 101.5 & 4.7 & 107.3 & 9.0 & 63.9 & 3.3 & 59.4 & 3.0 \\
\hline$\alpha$-Endosulfan & 100.6 & 4.1 & 107.1 & 9.5 & 63.7 & 3.4 & 57.3 & 2.5 \\
\hline cis-Chlordane & 114.9 & 4.2 & 113.9 & 9.8 & 70.0 & 4.0 & 64.2 & 2.8 \\
\hline$o, p^{\prime}-\mathrm{DDD}$ & 104.1 & 4.9 & 56.8 & 11.2 & 127.9 & 7.4 & 117.9 & 6.0 \\
\hline$\beta$-Endosulfan & 102.1 & 2.7 & 77.9 & 1.7 & 44.5 & 3.0 & 47.5 & 5.0 \\
\hline$o, p^{\prime}-\mathrm{DDT}$ & 108.8 & 2.4 & 86.9 & 12.1 & 63.7 & 4.2 & 53.0 & 1.4 \\
\hline
\end{tabular}

factors, including relatively ideal recoveries, low organic solvent volumes and short time.

Owing to the complex soil matrix and high extraction efficiency of MAE, it was important to reduce the number of interferences before chromatographic analysis, which could damage the chromatographic column and result in matrix effects (Zhang et al. 2011c). Recoveries of all 10 OCPs for the Florisil SPE cartridge, sulfonation and sorbent methods were in the ranges of $95.5 \%-114.9 \%$, $12.6 \%-76.1 \%$ and $31.5 \%-87.3 \%$, respectively, and the RSD ranged from $1.8 \%$ to $4.9 \%$ for SPE, $0.9 \%-3.7 \%$ for sulfonation and $3.0 \%-9.3 \%$ for sorbent (Fig. 1). Very low purification recoveries of $\alpha$-endosulfan $(40.2 \%)$ and $\beta$-endosulfan (12.6\%) were found when the sulfonation method was used. These low values could be attributed to the instability of endosulfan in sulfuric acid. We also found poor recoveries of $\beta-\mathrm{HCH} \quad(31.5 \%), \quad \beta$-endosulfan $(45.1 \%)$, and $o, p^{\prime}$-DDT $(37.0 \%)$ for sorbent purification, which could be due to the higher adsorption of these pesticides to the sorbent. Therefore, the SPE purification method was selected to analyze the real soil samples.

To evaluate the MAE-SPE method, recoveries from soil samples spiked at low and high concentrations were $60.6 \%-119.0 \%$ and $55.3 \%-109.0 \%$, respectively (Table 3). The overall reproducibility was evaluated and the relative standard derivation (RSD) values of OCPs were

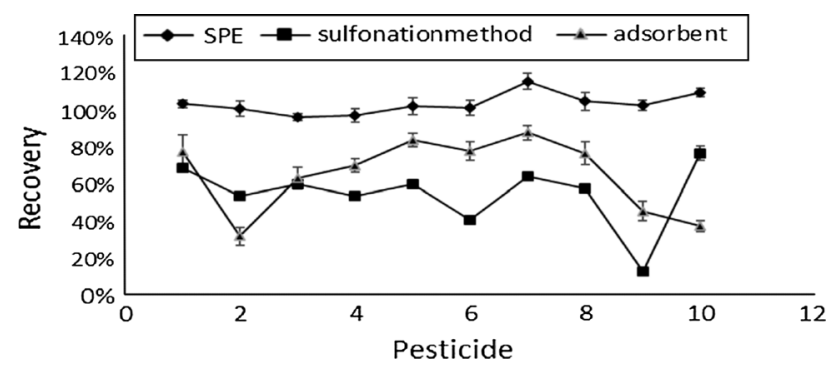

Fig. 1 Pesticide recoveries by three purification methods
Table 3 Recoveries of pesticides spiked into soil at two concentrations

\begin{tabular}{lrrrrr}
\hline & \multicolumn{2}{l}{$0.01 \mathrm{mg} / \mathrm{kg}$} & & $0.1 \mathrm{mg} / \mathrm{kg}$ \\
\cline { 2 - 3 } \cline { 5 - 6 } & $\mathrm{R}(\%)$ & $\mathrm{RSD}(\%)$ & & $\mathrm{R}(\%)$ & $\mathrm{RSD}(\%)$ \\
\hline$\alpha$-HCH & 109.6 & 2.7 & & 95.1 & 3.6 \\
$\beta-\mathrm{HCH}$ & 109.9 & 3.3 & & 92.3 & 4.6 \\
$\gamma$-HCH & 92.3 & 8.7 & & 70.2 & 2.0 \\
trans-Chlordane & 119.0 & 4.2 & & 56.7 & 3.0 \\
$o, p^{\prime}$-DDE & 93.0 & 12.0 & & 64.8 & 3.5 \\
$\alpha$-Endosulfan & 60.6 & 7.9 & & 62.4 & 2.3 \\
cis-Chlordane & 90.7 & 5.9 & & 66.7 & 3.3 \\
$o, p^{\prime}$-DDD & 99.6 & 5.9 & & 109.0 & 4.6 \\
$\beta$-Endosulfan & 89.5 & 7.8 & & 55.3 & 2.7 \\
$o, p^{\prime}$-DDT & 98.1 & 6.2 & & 63.2 & 4.5 \\
\hline
\end{tabular}

$\leq 12.0 \%$. Therefore, the reproducibility of the measurements was satisfactory, and the MAE-SPE method was considered to be both accurate and precise.

Linear calibration curves for all pesticides over five calibration levels, from 0.005 to $0.5 \mathrm{mg} / \mathrm{L}$ were constructed using TCMX as an internal standard. The calibration curves were linear over the whole concentration range tested for all the OCPs with coefficients of determination $\left(\mathrm{R}^{2}\right)$ over 0.9905 (Table 4). Limits of detection (LOD) and limits of quantitation (LOQ) were defined to be the pesticide concentrations at which the signal-to-noise ratios ( $\mathrm{S} /$ $\mathrm{N})$ were equal to three and ten, respectively. The LOD and LOQ of the pesticides ranged from $0.33-1.08$ to $1.09-3.61 \mu \mathrm{g} / \mathrm{kg}$, respectively (Table 4).

The MAE-SPE method was applied to measure trace levels of the 10 OCPs in 6 soil samples from Beijing. The results are shown in Table 5. Only $\alpha$-endosulfan and $\beta$ endosulfan (confirmed by GC-MS/MS) were not found in the 6 soil samples. Trans-chlordane was found in three 
Table 4 Matrix-matched calibration regression equations, coefficients of determination $\left(\mathrm{R}^{2}\right)$ and LOD and LOQ concentrations for 10 pesticides

\begin{tabular}{lllll}
\hline Pesticides & Regression equation & $\mathrm{R}^{2}$ & $\mathrm{LOD}(\mu \mathrm{g} / \mathrm{kg})$ & $\mathrm{LOQ}(\mu \mathrm{g} / \mathrm{kg})$ \\
\hline$\alpha$-HCH & $\mathrm{y}=12.021 \mathrm{x}+0.4464$ & 0.9956 & 0.35 & 1.17 \\
$\beta$-HCH & $\mathrm{y}=8.171 \mathrm{x}+1.133$ & 0.9905 & 0.82 & 2.73 \\
$\gamma$-HCH & $\mathrm{y}=15.91 \mathrm{x}+0.5256$ & 0.9960 & 0.46 & 1.53 \\
trans-Chlordane & $\mathrm{y}=36.428 \mathrm{x}+0.0416$ & 0.9999 & 0.33 & 1.09 \\
$o, p^{\prime}$-DDE & $\mathrm{y}=13.744 \mathrm{x}+0.2954$ & 0.9972 & 0.71 & 2.36 \\
$\alpha$-Endosulfan & $\mathrm{y}=31.501 \mathrm{x}+0.0702$ & 0.9998 & 0.38 & 1.28 \\
cis-Chlordane & $\mathrm{y}=21.58 \mathrm{x}-0.2574$ & 0.9983 & 0.43 & 1.42 \\
$o, p^{\prime}$-DDD & $\mathrm{y}=17.772 \mathrm{x}-0.1389$ & 0.9990 & 0.53 & 1.78 \\
$\beta$-Endosulfan & $\mathrm{y}=13.244 \mathrm{x}+0.5134$ & 0.9911 & 1.08 & 3.61 \\
$o, p^{\prime}$-DDT & $\mathrm{y}=31.335 \mathrm{x}+0.6502$ & 0.9964 & 1.03 & 3.43 \\
\hline
\end{tabular}

Table 5 Trace levels of 10 OCPs in six soil samples from Beijing analyzed using the MAE-SPE procedure

\begin{tabular}{|c|c|c|c|c|c|c|}
\hline Pesticides $(\mu \mathrm{g} / \mathrm{kg})$ & $\begin{array}{l}\text { Xiaotangshan } \\
1\end{array}$ & $\begin{array}{l}\text { Liulin } \\
2\end{array}$ & $\begin{array}{l}\text { Xixiaoying } \\
3\end{array}$ & $\begin{array}{l}\text { Shangzhuang reservoir } \\
4\end{array}$ & $\begin{array}{l}\text { CAU } \\
5\end{array}$ & $\begin{array}{l}\text { Tiangongyuan } \\
6\end{array}$ \\
\hline$\alpha-\mathrm{HCH}$ & 0.019 & 0.031 & 0.046 & 0.648 & 0.083 & 0.067 \\
\hline$\beta-\mathrm{HCH}$ & 0.015 & 0.041 & 0.01 & 0.181 & 0.053 & 0.061 \\
\hline$\gamma-\mathrm{HCH}$ & 0.035 & 0.056 & 0.033 & 1.093 & 0.257 & 0.046 \\
\hline trans-Chlordane & - & - & - & 0.014 & 0.007 & 0.003 \\
\hline$o, p^{\prime}-\mathrm{DDE}$ & 0.042 & 0.086 & 0.043 & 1.268 & 0.085 & 0.068 \\
\hline cis-Chlordane & - & - & - & - & 0.005 & 0.006 \\
\hline$\alpha$-Endosulfan & - & - & - & - & - & - \\
\hline$o, p^{\prime}-\mathrm{DDD}$ & - & 0.059 & - & 2.54 & 0.206 & 0.084 \\
\hline$o, p^{\prime}$-DDT & 0.467 & 0.551 & 0.569 & 17.616 & 2.983 & 0.518 \\
\hline$\beta$-Endosulfan & - & - & - & - & - & - \\
\hline $\mathrm{HCHs}$ & 0.07 & 0.128 & 0.089 & 1.923 & 0.393 & 0.174 \\
\hline DDTs & 0.508 & 0.695 & 0.613 & 21.424 & 3.274 & 0.67 \\
\hline$\alpha-\mathrm{HCH} / \gamma-\mathrm{HCH}$ & 0.554 & 0.553 & 1.377 & 0.592 & 0.323 & 1.455 \\
\hline$\alpha-\mathrm{HCH} / \beta-\mathrm{HCH}$ & 1.275 & 0.769 & 4.794 & 3.574 & 1.558 & 1.109 \\
\hline
\end{tabular}

$C A U$ China Agricultural University

samples and cis-chlordane was found in two samples, while $\alpha-\mathrm{HCH}, \beta-\mathrm{HCH}, \gamma-\mathrm{HCH}, o, p^{\prime}$-DDT and $o, p^{\prime}$-DDE were found in all six soil samples. The concentrations of total $\mathrm{HCHs}$ for all the sampling sites ranged from 0.07 to $1.92 \mu \mathrm{g} / \mathrm{kg}$. The concentrations of $\mathrm{HCHs}$ in all soils were comparatively lower than DDTs. There were two possible reasons. The first possibility may be that $\mathrm{HCHs}$ have lower lipophilicity and higher volatility and water solubility than DDTs (Zhang et al. 2013), and thus could be more easily transferred from surrounding soils into rivers, atmosphere and other environmental media. On the other hand, it may be due to their different amounts of application and production over the past decades (Zhu et al. 2005). The residue levels of DDTs in soils in Beijing were lower than those reported in Tianjin (average of $80 \mu \mathrm{g} / \mathrm{kg}$ ) (Tao et al. 2005), and Zhejiang (average of $86 \mu \mathrm{g} / \mathrm{kg}$ ) in China (Zhang et al. 2012a). The concentration levels of HCHs in Beijing were also much lower than those reported in other areas in China, such as Guangzhou (average of $\alpha-, \beta$ - and $\gamma-\mathrm{HCH}$ were $0.88,2.31$, and $0.76 \mu \mathrm{g} / \mathrm{kg}$ respectively) (Zhang et al. 2002). Strong correlations among $\alpha-, \gamma-$, and $\beta-\mathrm{HCH}$ $(\mathrm{R} \geq 0.959)$ suggested similar sources likely originated from historic use of technical HCHs.

The ratio of $\alpha-\mathrm{HCH} / \gamma-\mathrm{HCH}$ was between 5 and 7 in the technical HCHs and nearly zero for $\alpha-\mathrm{HCH} /$ lindane. The ratio of $\alpha-\mathrm{HCH} / \gamma-\mathrm{HCH}$ could be used to evaluate whether the source was from technical HCHs or lindane (Zhang et al. 2011a). HCH isomer ratios in each soil sample were shown in Table 5. The ratios of $\alpha-\mathrm{HCH} / \gamma-\mathrm{HCH}$ were all below 5.0 in this work, which indicated that $\mathrm{HCH}$ residues at these sites were most likely from historic use of technical $\mathrm{HCHs}$. The ratio of $\alpha-\mathrm{HCH} / \beta-\mathrm{HCH}$ was another useful indicator to assess if technical $\mathrm{HCHs}$ were recently applied in the region (Zhang et al. 2011a), as the ratio is 
approximately 11.8 for technical HCHs. From Table 5, the ratios of $\alpha-\mathrm{HCH} / \beta-\mathrm{HCH}$ in all samples were below that of technical HCHs. The results suggested that fresh application of technical HCHs in large quantities are not likely occurring in Beijing.

A procedure based on MAE-SPE had been developed for analysis of OCPs in soils. The high extraction efficiency of MAE combined with purification on Florisil-SPE column resulted in satisfactory recovery, clean chromatograms, and good selectivity and accuracy. Moreover, compared with other extraction methods, this method had advantages of shorter analysis time, lower solvent consumption, and greater automation. Therefore, it can be concluded that this is a promising method for the analysis of organochlorine pesticides as an alternative to traditional extraction techniques.

Acknowledgments This work was supported by funding from the National Natural Science Foundation of China (Contract Grant Number: 41201499) and National Science Foundation for Fostering Talents in Basic Research of China (No. J1210064).

\section{References}

Barriada-Pereira M, González-Castro M, Muniategui-Lorenzo S, López-Mahía P, Prada-Rodríguez D, Fernández-Fernández E (2007) Comparison of pressurized liquid extraction and microwave assisted extraction for the determination of organochlorine pesticides in vegetables. Talanta 71(3):1345-1351

Chikuni O, Nhachi C, Nyazema N, Polder A, Nafstad I, Skaare J (1997) Assessment of environmental pollution by PCBs, DDT and its metabolites using human milk of mothers in Zimbabwe. Sci Total Environ 199(1):183-190

Ganzler K, Salgó A, Valkó K (1986) Microwave extraction: a novel sample preparation method for chromatography. J Chromatogr A 371:299-306

Gebbink WA, Sonne C, Dietz R, Kirkegaard M, Born EW, Muir DC et al (2007) Target tissue selectivity and burdens of diverse classes of brominated and chlorinated contaminants in polar bears (Ursus maritimus) from East Greenland. Environ Sci Technol 42(3):752-759

Jia Y, Molstad L, Frostegård Å, Aagaard P, Breedveld GD, Bakken LR (2007) Kinetics of microbial growth and degradation of organic substrates in subsoil as affected by an inhibitor, benzotriazole: model based analyses of experimental results. Soil Biol Biochem 39(7):1597-1608

Loganathan BG, Kannan K (1994) Global organochlorine contamination trends-an overview. Ambio 23(3):187-191

Parera J, Santos F, Galceran M (2004) Microwave-assisted extraction versus Soxhlet extraction for the analysis of short-chain chlorinated alkanes in sediments. J Chromatogr A 1046(1):19-26
Pino V, Ayala JH, Afonso AM, González V (2000) Determination of polycyclic aromatic hydrocarbons in marine sediments by highperformance liquid chromatography after microwave-assisted extraction with micellar media. J Chromatogr A 869(1):515-522

Pozo K, Harner T, Lee SC, Wania F, Muir DC, Jones KC (2008) Seasonally resolved concentrations of persistent organic pollutants in the global atmosphere from the first year of the GAPS study. Environ Sci Technol 43(3):796-803

Srivastava L, Kumar N, Gupta K, Raizada R (2006) Status of HCH residues in Indian medicinal plant materials. Bull Environ Toxicol Chem 76(5):782-790

Tao S, Xu F, Wang X, Liu W, Gong Z, Fang J et al (2005) Organochlorine pesticides in agricultural soil and vegetables from Tianjin, China. Environ Sci Technol 39(8):2494-2499

Tao S, Liu W, Li Y, Yang Y, Zuo Q, Li B et al (2008) Organochlorine pesticides contaminated surface soil as reemission source in the Haihe Plain, China. Environ Sci Technol 42(22):8395-8400

Zhang G, Parker A, House A, Mai B, Li X, Kang Y et al (2002) Sedimentary records of DDT and $\mathrm{HCH}$ in the Pearl River Delta, south China. Environ Sci Technol 36(17):3671-3677

Zhang A, Liu W, Yuan H, Zhou S, Su Y, Li YF (2011a) Spatial distribution of hexachlorocyclohexanes in agricultural soils in Zhejiang province, China, and correlations with elevation and temperature. Environ Sci Technol 45(15):6303-6308

Zhang N, Yang Y, Tao S, Liu Y, Shi KL (2011b) Sequestration of organochlorine pesticides in soils of distinct organic carbon content. Environ Pollut 159(3):700-705

Zhang Y, Yang J, Shi R, Su Q, Gao Y, Zhu X (2011c) Development of an analytical method based on accelerated aolvent extraction, solidphase extraction clean-up, then GC-ECD for analysis of fourteen organochlorine pesticides in cereal crops. Chromatographia 73(3-4):385-391

Zhang A, Chen Z, Ahrens L, Liu W, Li YF (2012a) Concentrations of DDTs and enantiomeric fractions of chiral DDTs in agricultural soils from Zhejiang province, China, and correlations with total organic carbon and pH. J Agric Food Chem 60(34):8294-8301

Zhang W, Lv J, Shi R, Liao C (2012b) A rapid screening method for the determination of seventy pesticide residues in soil using microwave-assisted extraction coupled to gas chromatography and mass spectrometry. Soil Sediment Contam 21(4):407-418

Zhang F, He J, Yao Y, Hou D, Jiang C, Zhang X et al (2013) Spatial and seasonal variations of pesticide contamination in agricultural soils and crops sample from an intensive horticulture area of Hohhot, North-West China. Environ Monit Assess 185(8):6893-6908

Zhao Z, Xia L, Wang F, Jiang X, Gao Y (2012) Optimization of extractants, purifying packings, and eluents for analytical extraction of organochlorine pesticides in Hydragric Acrisols. Environ Monit Assess 184(8):5159-5171

Zhu Y, Liu H, Xi Z, Cheng H, Xu X (2005) Organochlorine pesticides (DDTs and HCHs) in soils from the outskirts of Beijing, China. Chemosphere 60(6):770-778

Zietz BP, Hoopmann M, Funcke M, Huppmann R, Suchenwirth R, Gierden E (2008) Long-term biomonitoring of polychlorinated biphenyls and organochlorine pesticides in human milk from mothers living in northern Germany. Int $\mathrm{J}$ Environ Health 211(5):624-638 